(C)2005 IEEE. Personal use of this material is permitted. However, permission to reprint/republish this material for advertising or promotional purposes or for creating new collective works for resale or redistribution to servers or lists, or to reuse any copyrighted component of this work in other works must be obtained from the IEEE. 


\title{
A Leakage-Inductance-Based ZVS Two-Inductor Boost Converter With Integrated Magnetics
}

\author{
Quan Li, Student Member, IEEE, and Peter Wolfs, Senior Member, IEEE,
}

\begin{abstract}
A two-inductor boost converter topology has conduction loss and transformer utilization advantages in converting low-voltage higher current inputs to high output voltages. In this letter, a new zero-voltage switching (ZVS) two-inductor boost converter with integrated magnetics is proposed. In the new topology, the two current source inductors, a resonant inductor and a two-winding transformer, are integrated into one single magnetic core with three windings. Two windings simultaneously perform the functions of the current source inductors and the transformer primary. The transformer leakage inductance forms the resonant inductance. This leads to a much more compact converter design with a significant reduction in the number of core and winding components. A theoretical analysis establishes the operating point of the ZVS converter. Both of the theoretical and experimental waveforms, including flux waveforms for the legs of the integrated core structure, are presented at the end of the letter.
\end{abstract}

Index Terms-Integrated magnetics, two-inductor boost converter, zero-voltage switching (ZVS).

\section{INTRODUCTION}

$\mathbf{T}$ HE two-inductor boost converter is well suited for low-voltage input, high-voltage output applications [1]. In order to combat the parasitic effects of the transformer leakage inductance in the hard-switched converter, a zero-voltage switching converter has been developed [2]. Fig. 1 shows the ZVS two-inductor boost converter with a voltage doubler rectifier. The quasiresonant converter is able to use the transformer leakage inductance and the MOSFET output capacitance as part of the resonant elements. This allows the switches to turn on at zero voltage and theoretically eliminates the switching losses. Higher efficiencies can be achieved under high switching frequencies and the converter volume and weight are minimized. However, the converter does require one additional resonant inductor and two additional resonant capacitors to form a resonant network [2]. This, in conjunction with the three existing magnetic cores required for the two inductors and the one transformer, contributes to bulk and weight.

This letter proposes a new ZVS two-inductor boost converter with integrated magnetics. In this topology, the two inductors and the one transformer are implemented with three copper windings on a single magnetic core and the resonant inductance is purely formed by the transformer leakage inductance. Compared with the discrete magnetics approach, the proposed converter has a significantly smaller component count and

Manuscript received November 17, 2004; revised February 11, 2005. Recommended by Associate Editor J. A. Cobos.

The authors are with the Faculty of Engineering and Physical Systems, Central Queensland University, Rockhampton Mail Center, QLD 4702, Australia (e-mail: q.li@cqu.edu.au; p.wolfs@cqu.edu.au).

Digital Object Identifier 10.1109/LPEL.2005.846823

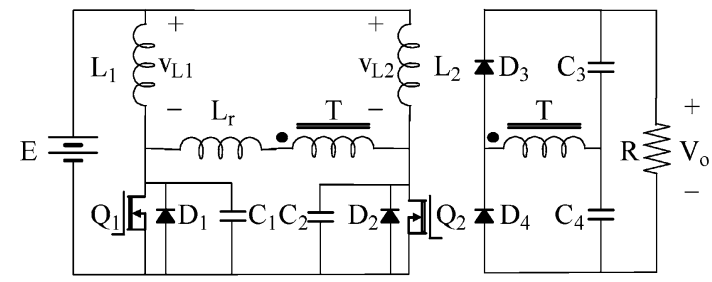

Fig. 1. ZVS two-inductor boost converter.

fewer interconnections between the windings. This results in a more compact design with a higher power density and better cost effectiveness.

\section{ZVS Two-INDUCTOR BOOOST CONVERTER WITH INTEGRATED MAGNETICS}

The demand for three separate magnetic components in the two-inductor boost converter tends to depart from the philosophy of "more silicon and less iron" in the design of the modern power electronic converters [3]. The last two decades have seen increasing interest in magnetic integration including both core and winding integration techniques [4], [5]. Among these, one particular application uses a core with three windings to implement a transformer and the two inductors in a current-doubler rectifier circuit [6]. In this application, the low-voltage transformer secondary and the individual inductor windings are integrated into a single winding located on each of the outer legs of a planar E core.

The current-doubler rectifier is related to the two-inductor boost converter by the principle of bilateral inversion [7]. If the diodes of the current doubler rectifier are replaced with active devices and the power flow reversed, a two-inductor boost converter results. As the primary side of the two-inductor boost converter shares a similar topology with the current doubler rectifier, the integrated magnetic scheme employed in [6] can be adopted by the two-inductor topology to merge the two input inductors and the one transformer into a single core with three windings.

The original current-doubler rectifier circuit using an integrated magnetic solution features a significant level of leakage inductance for the equivalent transformer as the primary and secondary windings are placed on different core legs. The current-doubler rectifier solution was proposed as a hard-switched converter [6]. The major effect of the leakage inductance in that application is a diode commutation overlap which reduces the available output voltage. The MOSFETs do not encounter over-voltage at turn-off as the current in one MOSFET is naturally taken by the body diode of the other. In the two-inductor 


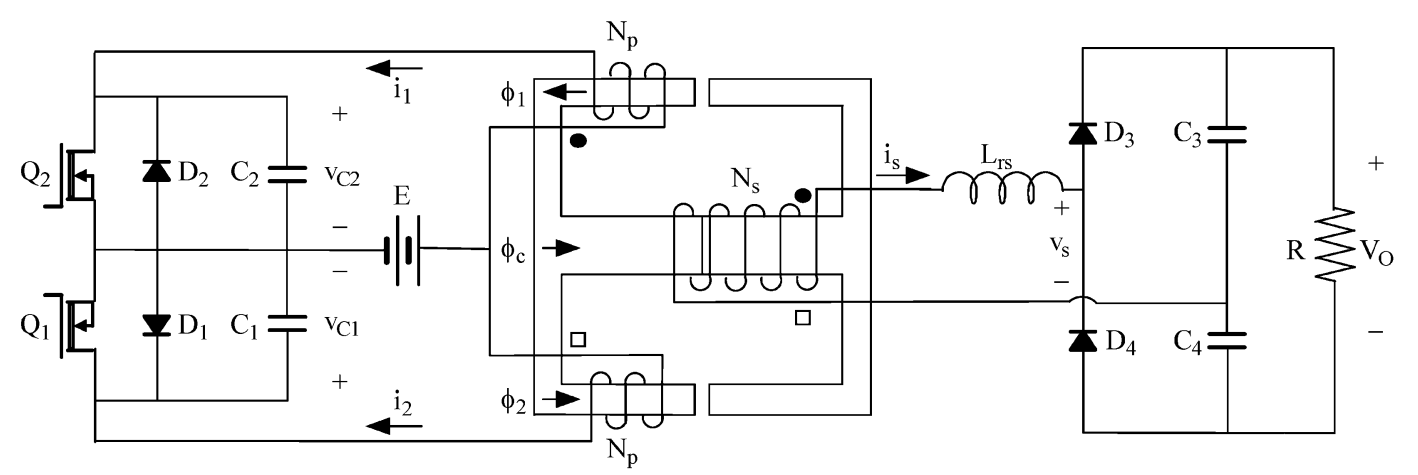

Fig. 2. ZVS two-inductor boost converter with integrated magnetics.

boost converter, however, the transformer leakage inductance resonates with the MOSFET output capacitance and causes over voltage across the MOSFET. Therefore, this converter is much less tolerant of the leakage inductance in its hard-switched form. A ZVS topology was developed to overcome this disadvantage [2], and this also can be applied to the integrated magnetics case. Fig. 2 shows the proposed ZVS two-inductor boost converter with integrated magnetics.

The two input inductors $\mathrm{L}_{1}, \mathrm{~L}_{2}$ and the transformer T in Fig. 1 are implemented by three windings on one three-leg magnetic core. The two windings on the outer legs function as the inductors as well as the transformer primary. The equivalent magnetic circuit is shown in Fig. 3(a). $\mathrm{N}_{\mathrm{p}}$ and $\mathrm{N}_{\mathrm{s}}$ are, respectively, the number of turns of the outer-leg and the center-leg windings. The instantaneous fluxes in each core leg are, respectively, $\phi_{1}, \phi_{2}$, and $\phi_{c} . \Re_{\mathrm{o}}$ and $\Re_{\mathrm{c}}$ are, respectively, the magnetic reluctances of the outer core leg and the center core leg. Applying the duality principle to the magnetic circuit in Fig. 3(a) and rescaling the circuit parameters as elaborated in [7], the equivalent electrical model of the magnetic structure in Fig. 2 can be obtained in the discrete magnetic form, as shown in Fig. 3(b). Unlike the conventional transformer designs, the outer legs of this magnetic core must be gapped to store the energy as required in the inductor designs and the equivalent input inductance of the converter is inversely proportional to the length of the gap.

In Fig. 2, $\mathrm{D}_{1}$ and $\mathrm{D}_{2}$ are, respectively, the reverse body diodes of the MOSFETs $\mathrm{Q}_{1}$ and $\mathrm{Q}_{2}$. The resonant inductance $L_{\mathrm{rs}}=$ $\left(N_{s} / N_{p}\right)^{2} L_{r}$ is purely realized by the transformer leakage inductance referred to the transformer secondary side. No additional resonant inductors are required. The resonant capacitances $C_{1}=C_{2}$ are made up from the MOSFET output capacitances and the additional capacitors with low dissipation factors in parallel with the MOSFET.

A two-inductor boost converter with a single magnetic core but four windings has been previously proposed in [8]. This approach provides a design with relatively low transformer leakage inductance values especially in planar cores. A lower leakage design is a pre-requisite for the hard-switched applications. If a resonant converter is desired the higher leakage inductance of the three winding structure can be useful.

A two-inductor boost converter with an auxiliary transformer has also been proposed [9]. In this topology the voltage regulation range is considerably extended. Recently, an active snubber

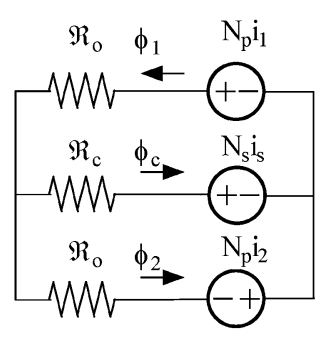

(a)

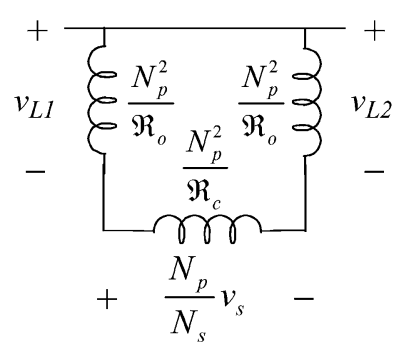

(b)
Fig. 3. Integrated magnetics. (a) Equivalent magnetic circuit. (b) Equivalent electrical model.

has been proposed for the converter with an auxiliary transformer to control the output rectifier losses and provide a soft switching condition for the two input switches [10]. The design limits the diode turn-off $d i / d t$ and both turn-on and turn-off $d i / d t$ for the main switches.

The resonant solution proposed in this letter offers ZVS for the main switches and additionally offers inherently favorable operating conditions for the output rectifiers which now process currents that are close to a sinusoidal waveform over the converter operating cycle and have even lower $d i / d t$ values at their zero crossing. The ZVS two-inductor boost converter proposed is galvanically isolated by a high-frequency transformer with a simple magnetic structure. The design actively uses the major circuit parasitic components including transformer leakage and MOSFET capacitance to achieve a very low component count.

\section{BASIC PRINCIPLES OF OPERATION}

As the two-inductor boost converter with integrated magnetics can be modeled by the converter with discrete magnetics as shown in Fig. 3(b), the operation can be analyzed based on the converter in Fig. 1 if the resonant inductance $\mathrm{L}_{\mathrm{rs}}$ is converted to its equivalent value $\mathrm{L}_{\mathrm{r}}$ on the transformer primary side. The duty ratios of the MOSFETs $\mathrm{Q}_{1}$ and $\mathrm{Q}_{2}$ must be greater than $50 \%$ to ensure the continuity of the flux in each leg of the magnetic core. According to Fig. 2, the fluxes in the two outer core legs are restricted by the following equations:

$$
\begin{aligned}
& N_{p} \frac{d \phi_{1}}{d t}=E-v_{C 2} \\
& N_{p} \frac{d \phi_{2}}{d t}=E-v_{C 1} .
\end{aligned}
$$




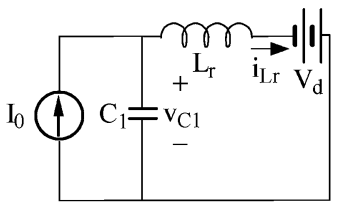

State (a)

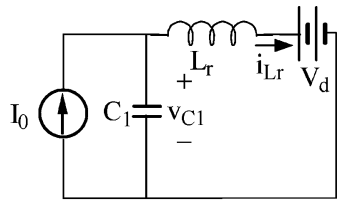

State (c)

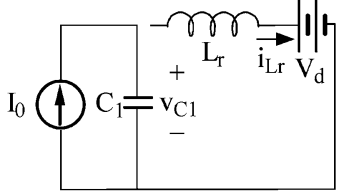

State (b)

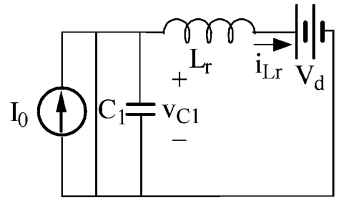

State (d)
Fig. 4. Four possible states.

The analysis is only demonstrated for the cycle from $Q_{1}$ turn-off to $\mathrm{Q}_{2}$ turn-off. After $\mathrm{Q}_{2}$ turns off, the converter will move through a similar group of states. The resonant capacitor voltage and the flux in the outer leg will be the same while the resonant inductor current or the transformer primary current will be reversed. Before $\mathrm{Q}_{1}$ turns off, both $\mathrm{Q}_{1}$ and $\mathrm{Q}_{2}$ are closed. At time $t=0, \mathrm{Q}_{1}$ turns off and the converter will move up to four possible states before $Q_{2}$ turns off, as shown in Fig. 4, [2]. $\mathrm{I}_{0}$ is the current in the inductors $\mathrm{L}_{1}$ or $\mathrm{L}_{2}$ and $\mathrm{V}_{\mathrm{d}}$ is the output capacitor $\mathrm{C}_{3}$ or $\mathrm{C}_{4}$ voltage reflected to the winding that performs as both the inductance and the transformer primary.

1) State (a) $\left(0 \leq t \leq t_{1}\right)$ : This state only exists if the resonant inductor carries a nonzero current when the MOSFET $\mathrm{Q}_{1}$ turns off. The initial conditions are $i_{L r}(0)=-\Delta_{1} \cdot I_{0}, v_{C 1}(0)=$ 0 , and $\phi_{2}(0)=\Phi_{20}$, where $\Delta_{1}$ is the ratio of the initial inductor current to the current source $\mathrm{I}_{0}$ and $\Phi_{20}$ is the initial flux. Both the current source $\mathrm{I}_{0}$ and the resonant inductor current charge the capacitor $\mathrm{C}_{1}$. While $\mathrm{v}_{\mathrm{C} 1}$ increases, $\phi_{2}$ increases but with a reducing rate as long as $v_{C 1}<E$. When $v_{C 1}>E, \phi_{2}$ decreases with an increasing rate. The capacitor voltage $\mathrm{v}_{\mathrm{C} 1}$, the inductor current $i_{L r}$ and the flux $\phi_{2}$ are as shown in (3)-(5), at the bottom of the page, where $Z_{0}=\sqrt{L_{r} / C_{1}}$ is the characteristic impedance and $\omega_{0}=1 / \sqrt{L_{r} C_{1}}$ is the angular resonant frequency of the resonant tank.
2) State (b) $\left(t_{1} \leq t \leq t_{2}\right)$ : This state starts when the resonant inductor current reaches zero and will be bypassed if the resonant capacitor voltage is greater than $\mathrm{V}_{\mathrm{d}}$ at this point. In this state, only the current source charges the capacitor. The capacitor voltage increases linearly while the inductor current stays at zero. The flux $\phi_{2}$ encounters the same situation as in State (a). The capacitor voltage $\mathrm{v}_{\mathrm{C} 1}$, the inductor current $\mathrm{i}_{\mathrm{Lr}}$ and the flux $\phi_{2}$ are

$$
\begin{aligned}
v_{C 1} & =\frac{I_{0}}{C_{1}}\left(t-t_{1}\right)+v_{C 1}\left(t_{1}\right) \\
i_{L r}(t) & =0 \\
\phi_{2}(t) & =\frac{\left(E-v_{C 1}\left(t_{1}\right)\right)\left(t-t_{1}\right)-\frac{I_{0}}{2 C_{1}}\left(t-t_{1}\right)^{2}}{N_{p}}+\phi_{2}\left(t_{1}\right) .
\end{aligned}
$$

3) State (c) $\left(t_{2} \leq t \leq t_{3}\right)$ : In this state, the circuit starts to establish a resonant inductor current in the positive direction when the inductor resonates with the capacitor. The flux $\phi_{2}$ keeps decreasing with an increasing rate until $\mathrm{v}_{\mathrm{C} 1}$ reaches its peak and continues to decrease as long as $v_{C 1}>E$. After $\mathrm{v}_{\mathrm{C} 1}$ falls below $\mathrm{E}, \phi_{2}$ again increases at an increasing rate. The capacitor voltage $\mathrm{v}_{\mathrm{C} 1}$, the inductor current $\mathrm{i}_{\mathrm{Lr}}$ and the flux $\phi_{2}$ are as shown in (9)-(11), at the bottom of the page. If $k$ is defined by $I_{0} Z_{0}=k V_{d}$, a simplified ZVS condition is $k \geq 1$ according to (9). Equation (9) also determines the peak MOSFET voltage, which must be controlled within a reasonable level to allow an affordable MOSFET with a low forward resistance to be applied.

4) State $(d)\left(t_{3} \leq t \leq t_{4}\right)$ : At the beginning of this state, the capacitor voltage reaches zero and the MOSFET $\mathrm{Q}_{1}$ turns on. The resonant inductor is discharged linearly by $\mathrm{V}_{\mathrm{d}}$. The flux $\phi_{2}$ increases linearly. The capacitor voltage $\mathrm{v}_{\mathrm{C} 1}$, the inductor current $i_{L r}$ and the flux $\phi_{2}$ are

$$
\begin{aligned}
v_{C 1}(t) & =0 \\
i_{L r}(t) & =i_{L r}\left(t_{3}\right)-\frac{V_{d}}{L_{r}}\left(t-t_{3}\right) \\
\phi_{2}(t) & =\frac{E}{N_{p}}\left(t-t_{3}\right)+\phi_{2}\left(t_{3}\right) .
\end{aligned}
$$

$$
\begin{aligned}
v_{C 1}(t) & =\left(1+\Delta_{1}\right) I_{0} Z_{0} \sin \left(\omega_{0} t\right)+V_{d} \cos \left(\omega_{0} t\right)-V_{d} \\
i_{L r}(t) & =\frac{V_{d}}{Z_{0}} \sin \left(\omega_{0} t\right)-\left(1+\Delta_{1}\right) I_{0} \cos \left(\omega_{0} t\right)+I_{0} \\
\phi_{2}(t) & =\frac{\left(E+V_{d}\right) \omega_{0} t+\left(1+\Delta_{1}\right) I_{0} Z_{0}\left(\cos \left(\omega_{0} t\right)-1\right)-V_{d} \sin \omega_{0} t}{\omega_{0} N_{p}}+\Phi_{20}
\end{aligned}
$$

$$
\begin{aligned}
v_{C 1}(t) & =I_{0} Z_{0} \sin \omega_{0}\left(t-t_{2}\right)+\left(v_{C 1}\left(t_{2}\right)-V_{d}\right) \cos \omega_{0}\left(t-t_{2}\right)+V_{d} \\
i_{L r}(t) & =\frac{v_{C 1}\left(t_{2}\right)-V_{d}}{Z_{0}} \sin \omega_{0}\left(t-t_{2}\right)-I_{0} \cos \omega_{0}\left(t-t_{2}\right)+I_{0} \\
\phi_{2}(t) & =\frac{\left(E-V_{d}\right) \omega_{0}\left(t-t_{2}\right)+I_{0} Z_{0}\left(\cos \omega_{0}\left(t-t_{2}\right)-1\right)-\left(v_{C 1}\left(t_{2}\right)-V_{d}\right) \sin \omega_{0}\left(t-t_{2}\right)}{\omega_{0} N_{p}}+\phi_{2}\left(t_{2}\right) .
\end{aligned}
$$



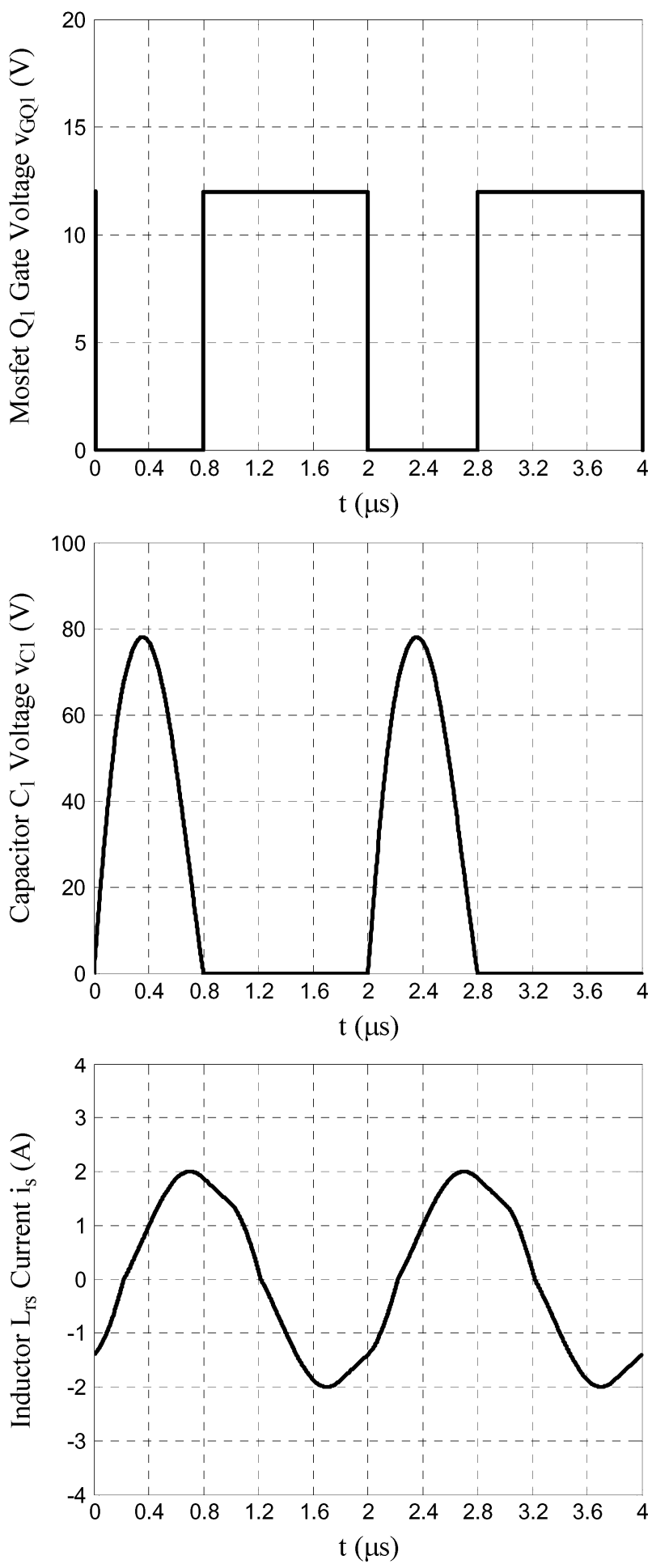

Fig. 5. Theoretical waveforms.

As the resonant inductance in Fig. 2 is the winding leakage inductance, the center leg flux obeys

$$
N_{s} \frac{d \phi_{c}}{d t}=v_{s}
$$

When the secondary current is positive, $v_{s}>0$ and $\phi_{\mathrm{c}}$ increases linearly, and vice versa. Due to the loose coupling of the primary and secondary windings, the leakage flux is significant and the

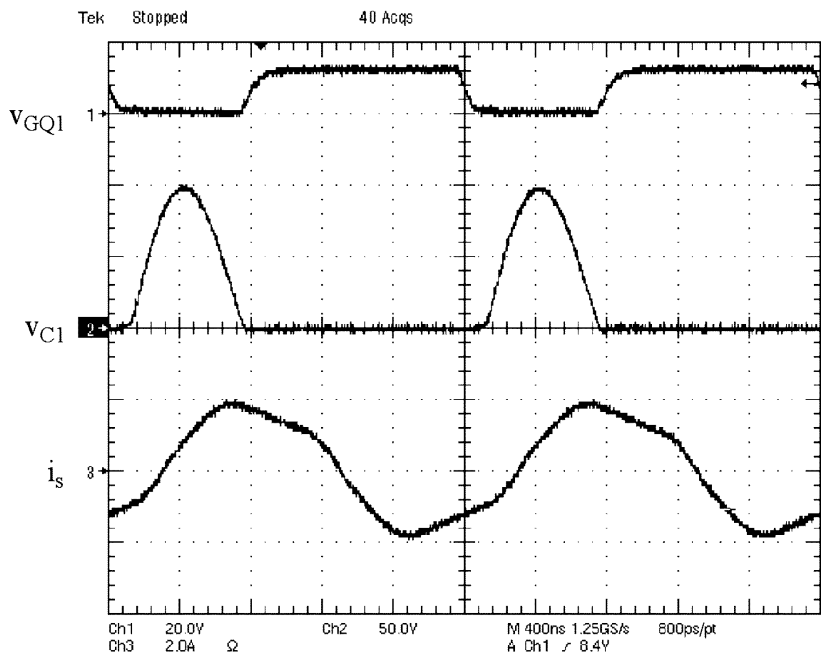

Fig. 6. Experimental waveforms.

flux paths are not constrained within the core structure. Therefore

$$
\phi_{c}=\phi_{1}-\phi_{2}+\phi_{\mathrm{le}}
$$

where $\phi_{\text {le }}$ is the leakage flux in the air.

\section{THEORETICAL AND EXPERIMENTAL WAVEFORMS}

The proposed topology is validated experimentally by a $20-\mathrm{V}$ input 40-W converter. A conversion efficiency of $93 \%$ has been recorded by using the mathematics functions of a Tektronix TDS5034 oscilloscope equipped with input and output voltage and current probes. The key components and parameters used in the converter are listed below.

- The two inductors and the transformer are implemented on a Philips ETD29 core with 0.5-mm air gaps in both outer legs. $N_{p}=10$ turns and $N_{s}=13$ turns. The transformer leakage inductance referred to the secondary is $12.5 \mu \mathrm{H}$.

- The switching frequency $f_{s}=500 \mathrm{kHz}$ and the duty ratio $D=0.6$.

- $\quad k=1.4, \Delta_{1}=1.9$, and $V_{d} / E=1.15$.

- $L_{r}=7.4 \mu \mathrm{H}$ and $C_{1}=C_{2}=6.6 \mathrm{nF}$.

The theoretical waveforms under the above operating conditions are presented in Fig. 5. The corresponding experimental waveforms are shown in Fig. 6. From top to bottom, Figs. 5 and 6 show the MOSFET gate voltage, the resonant capacitor voltage and the transformer secondary current. These agree very well and the ZVS two-inductor boost converter with the new magnetic structure clearly operates in the same manner as a resonant converter constructed with discrete components.

The top two waveforms in Fig. 7 are, respectively, the ac flux waveforms of $\phi_{2}$ and $\phi_{\mathrm{c}}$ as recovered by integrating the voltage of a single search turn wound on the transformer leg. The bottom two waveforms are, respectively, the resonant capacitor voltage $\mathrm{v}_{\mathrm{C} 1}$ and resonant inductor current $\mathrm{i}_{\mathrm{s}}$ and they are repeated here as references for the flux waveforms. It can be observed that $\phi_{2}$ decreases when $\mathrm{v}_{\mathrm{C} 1}$ is greater than $\mathrm{E}$ and $\phi_{\mathrm{c}}$ increases linearly when $i_{s}>0$ and decreases linearly when $i_{s}<0$. 


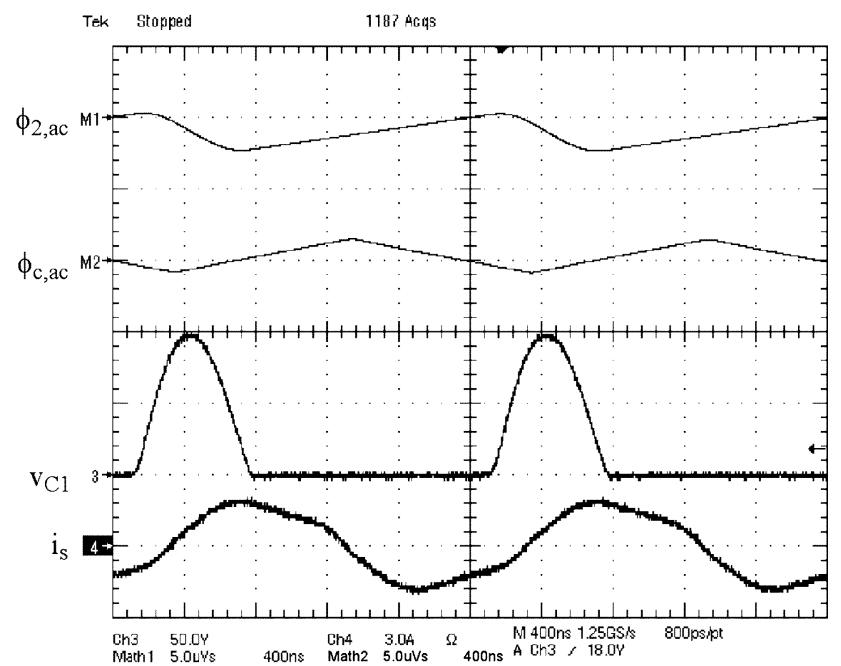

Fig. 7. Experimental waveforms.

\section{CONCLUSION}

A new soft-switched two-inductor boost converter with integrated magnetics is presented. The converter utilizes one magnetic core and three winding coils to implement the two inductors and one transformer. The transformer leakage inductance functions as the resonant inductance and no extra resonant inductors are required. Therefore, a minimum magnetic component count is achieved in the ZVS converter. The theoretical analysis of the converter operation is briefly provided. The experimental waveforms from a $40-\mathrm{W}$ proof-of-concept prototype converter validate the theoretical analysis.

\section{REFERENCES}

[1] P. J. Wolfs, "A current-sourced dc-dc converter derived via the duality principle from the half-bridge converter," IEEE Trans. Ind. Electron., vol. 40, no. 1, pp. 139-144, Feb. 1993.

[2] P. Wolfs and Q. Li, "An analysis of a resonant half bridge dual converter operating in continuous and discontinuous modes," in Proc. IEEE PESC, 2002, pp. 1313-1318.

[3] Y. Xue, L. Chang, S. B. Kjær, J. Bordonau, and T. Shimizu, "Topologies of single-phase inverters for small distributed power generators: An overview," IEEE Trans. Power Electron., vol. 19, pp. 1305-1314, Sep. 2004.

[4] G. Bloom and R. Severns, "The generalized use of integrated magnetics and zero-ripple techniques in switchmode power converters," in Proc. IEEE PESC, 1984, pp. 15-33.

[5] W. Chen, "Low Voltage High Current Power Conversion with Integrated Magnetics," Ph.D. dissertation, Virginia Polytechnic Inst. and State Univ., Blacksburg, 1998.

[6] W. Chen, G. Hua, D. Sable, and F. Lee, "Design of high efficiency, low profile, low voltage converter with integrated magnetics," in Proc. IEEE APEC, 1997, pp. 911-917.

[7] R. P. Severns and G. E. Bloom, Modern DC-to-DC Switchmode Power Converter Circuits. New York: Van Nostrand, 1985.

[8] L. Yan and B. Lehman, "Isolated two-inductor boost converter with one magnetic core," in Proc. IEEE APEC, 2003, pp. 879-885.

[9] Y. Jang and M. M. Jovanovic, "New two-inductor boost converter with auxiliary transformer," IEEE Trans. Power Electron., vol. 19, no. 1, pp. 169-175, Jan. 2004.

[10] - "A new soft-switched DC-DC front-end converter for applications with wide-range input voltage from battery power sources," in Proc. 25th Int. Telecommunications Energy Conf., 2003, pp. 770-777. 